\title{
Comienzo del Siglo XXI y Ciencias Sociales: Un rompecabezas posible
}

\author{
Adrian Scribano ${ }^{1}$ \\ Universidad de Buenos Aires, Buenos Aires, Argentina. \\ Email: adrianscribano@gmail.com
}

\begin{abstract}
Resumen: El objetivo de este trabajo es presentaralgunas de las múltiples aristas de los desafíos que contiene el siglo XXI para las Ciencias Sociales. Para ello propone "jugar" con la idea de una mesa/superficie y cuatro piezas,y tomar el siguiente camino de ensamble: 1) identificar los rasgos sobresalientes de los procesos de estructuración social en tanto superficie de "juego"; 2) seleccionar tres componentes de las estructuras de las sensibilidades que conforman una pieza recortada al talle de la "lógica del desecho", "las políticas de la perversión” y "la banalización del bien”; 3) apartar en la composición de la figura, un esbozo de lo que implican el "saber tocar" y el "subsiadiano"; 4) esquematizar los "retos" a nivel de la metodología, la teoría y la epistemología de las formas señaladas, en su rol de componentes claves del "ensamblado"; y 5) finalmente "armar" el rompecabezas re-marcando "lo necesario de seguir rechazando".
\end{abstract}

Palabras clave: sensibilidades, principio de siglo, saber tocar, teoría.

\section{Beginning of the XXI Century and Social Sciences: A possible puzzle}

\begin{abstract}
The aim of this paper is to present some of the many facets of the challenges that contains the XXI century for the Social Sciences. In doing so, it proposes to "play" with the idea of ??a table/surface and four pieces, and to take the followingpathof assembly: 1) identify the salient features of the processes of social structuring as surface of the "game"; 2) select three components of the sensitivity structures that conform a cut at the waist of the piece of the "wastelogic", "politics of perversion" and "banality of the good"; 3) separate in the composition of the figure an outline of the implications of "knowing how to touch" and the "subsiadiano"; 4) outline the "challenges" in terms of methodology, theory and epistemology of the aforementioned forms, in their role as key components of the "assembly"; and 5) finally "construct" the puzzlere-marking "what is necessary to continue rejecting".
\end{abstract} theory.

Keywords: sensibilities, beginning of the century, knowing how to touch,

\section{Início do século XXI e Ciências Sociais: Um quebra-cabeça possível}

Resumo: O objetivo deste artigo é apresentar algumas das muitas facetas dos desafios que contém o século XXI para as Ciências Sociais. Ele propoe "brincar” com a idéia de uma mesa/superfície e quatro peças, e tomao seguinte caminho de emsamble: 1) identificar as principais características dos processos de estruturação 
social entanto superfície do "jogo"; 2) selecionar três componentes das estruturas das sensibilidades que conformam uma peça cortada na "lógica de resíduos”, “as políticas daperversão" e "a banalidade do bem”; 3) afastar na composição da figura, um esboço do que envolve"saber tocar" e o "subsiadiano"; 4) delinear os "desafios" em termos da metodologia, a teoria ea epistemologia das formas acima mencionadas, no seu papel de componentes-chave da "ensamblagem”; e 5) finalmente "armar” o quebra-cabeça remarcando"o preciso para continuar rejeitando”.

Palavras-chave: sensibilidades, início do século, saber tocar, teoria.

\section{Introducción}

Destutt de Tracy escribió entre 1801 y 1815 "Elementos de Ideología...” y Max Weber redacta lo que nosotros conocemos como sus "escritos metodológicos” entre 1904 y 1905, es decir, las Ciencias Sociales y la Sociología son prácticas académicas y del conocer que en estos primeros 15 años del Siglo XXI están comenzando sus 300 años. Son múltiples las transformaciones que se han efectuado en las sociedades desde el comienzo del siglo XIX y también numerosas y complejas las que desafían a nuestras disciplinas en la actualidad.

El objetivo de este trabajo es presentar, a modo de "puzzle indeterminado"2, algunas de las múltiples aristas de los desafíos que creemos contiene el siglo XXI para las Ciencias Sociales. Para ello jugaremos con una mesa/superficie y cuatro piezas tomando el siguiente camino de ensamble: 1) identificaremos, de modo aproximado, los rasgos sobresalientes de los procesos de estructuración social en tanto superficie de "juego"; 2) continuaremos seleccionado tres componentes de las estructuras de las sensibilidades que conforman una pieza recortada al talle de la "lógica del desecho", las “políticas de la perversión” y la "banalización del bien”; 3) apartaremos en la composición de la figura, un esbozo de lo que implican el "saber tocar" y el "subsiadiano"; 4) esquematizamos los "retos" a nivel de la metodología, la teoría y la epistemología de las formas señaladas, en su rol de componentes claves del "armado"; y 5) procuramos"armar" el rompecabezas re-marcando "lo necesario de seguir rechazando".

Dado el carácter y el espacio para el presente escrito hemos incorporado las referencias bibliográficas mínimas para optimizar la posibilidad de hacer ver la mayor cantidad de aristas de lo que consideramos puede constituir un puzzle de la estructuración social de comienzo de siglo ${ }^{3}$.

\section{Aproximaciones a los procesos de estructuración}

Los procesos de estructuración social del comienzo del siglo XXI, que afectan la constitución de las ciencias sociales, pueden ser caracterizados de diversas maneras: en una primera aproximación desde una mirada global/planetaria y en una segunda desde un diagnóstico desde el Sur 
Global. Ambos acercamientos con-forman los contextos/escenarios/superficies donde se "ponen-en-juego" las piezas del puzzle que pretendemos construir.

Si nos detenemos en una mirada global/planetaria se destacan tres rasgos del estado actual de lo que hemos llamado, por lo menos hasta el siglo XX, la humanidad:

a) Los seres humanos somos la única especie que se puede autodestruir totalmente. Somos la única especie que desvincula planificadamente la conexión entre reproducción y sexualidad, siendo también los únicos que podemos diseñar genéticamente nuestra propia constitución. Tal vez sean estas las tres grande "revoluciones" del siglo XX que marcaran nuestro siglo XXI, y cuyos impactos en la sociedad producirán seguramente múltiples transformaciones en las ciencias sociales.

b) La relatividad, la cuántica, la complejidad y las teorías sobre el caos han transformado radicalmente, en el transcurso del siglo pasado, la estructura, procedimientos y metas de las ciencias en general, cuestión que con seguridad modificaran las ciencias sociales del siglo XXI.

c) El aumento de la población mundial, de los miles de millones de sujetos con hambre, de los miles de millones sin energía(s), de la ingente cantidad de sujetos esclavizados, de los millones de sujetos en estado de migración segregante, el crecimiento sostenido de la desigualdad planetaria, los miles de millones de mujeres, niños, jóvenes y personas de la tercera edad violentados, maltratados y marginalizados indican claramente que el siglo XXI implica un tiempo de nuevos desafíos para las ciencias sociales en su intento de observar y comprender las múltiples consecuencias que se desprenden de los hechos citados.

En relación a una aproximación desde el Sur Global es posible identificar los siguientes componentes de un diagnóstico de las sociedades normalizadas en el disfrute inmediato a través del consumo, en consonancia con la expansión del capital:

Las prácticas de depredación de los bienes comunes, la elaboración de los mecanismos de soportabilidad social y los dispositivos de regulación de las sensaciones y las redefiniciones de la represión-militarización de las sociedades. Estos tres ejes dibujan una primera y fundamental superficie donde se insertan los componentes del puzzle en una dialéctica helicoidal de expropiación, depredación energética, fantasmas, fantasías sociales y represión. Así, en la expansión global del capitalismo se puede constatar la constitución trinitaria de una religión del desamparo, de una religión neo-colonial que opera como componente fundamental de la economía política de la moral vigente. Para garantizar la operatividad de las aludidas prácticas ideológicas la política (institucional) debe crear la nueva religión de los países neocoloniales dependientes que reemplace la -ya antigua- trinidad de la "religión industrial”, basada en producción ilimitada, 
absoluta libertad y felicidad sin restricciones, por la trinidad de los expulsados compuesta por el consumo mimético, el solidarismo y la resignación. Nueva religión cuya liturgia es la construcción de las fantasías sociales, donde los sueños cumplen una función central en tanto reino de los cielos en la tierra, y la sociodicea de la frustración el papel de narrar y hacer presentes-aceptables los fantasmáticos infiernos del pasado vuelto presente continuo.

La mesa está dibujada, las superficies delineadas. Descriptos los escenarios avancemos ahora en bosquejar las formas de las piezas del rompecabezas.

\section{Estructura de la sensibilidad al principio de un siglo}

Una de las claves de todo proceso de estructuración social es el estado de la economía política de la moral y ésta- en los primeros años del siglo - se ha transformado acelerada y profundamente. Estas modificaciones recortan una figura básica para comprender el principio de siglo y armar el rompecabezas que lo "represente".

Hoy, en un acto pornográfico de la reproducción sistémica, las sensibilidades no se ocultan más en tanto las mercancías centrales del mundo y del Sur Global. Los "giros afectivos" (proclamados por muchos) son formas de adecuación de las prácticas académicas a las exigencias del mercado. El marketing ha reabsorbido las lecciones de los últimos 60 años de ciencias sociales: la centralidad de la "experiencia" como objeto mercantilizable, la potencialidad de la creatividad como vehículo para expresar/indagar el mundo social, y la preeminencia de nuevas políticas de los sentidos

Hoy, al igual que a principios del XX, las "nuevas" tecnologías se usan para: alcanzar cada vez mejores articulaciones entre deseos, objetos y subjetividades, para profundizar las sociabilidades normalizadas en el disfrute inmediato a través del consumo y crear vínculos, cada vez más fuertes, entre las vivencialidades y sensibilidades espectaculares/sacrificiales.

El "espectáculo" es una condición de las nuevas sacrificialidades dispuestas a través de los juegos de las afectividades: a) la pornografía del desecho, b) las políticas de la perversión y c) la banalización del bien a través del cinismo.

Una sociedad normalizada en el disfrute inmediato a través del consumo en el contexto de la depredación como estructura de reproducción sistémica, la religión neo-colonial en tanto contenido de la economía política de la moral y la espectacularización de lo social establece como lógica de interrelación social a las “prácticas del desechar”. Es posible entender estas prácticas siguiendo las huellas del análisis que realizaron tanto Weber como Adorno y Horkheimer respecto al lugar de la racionalidad ins- 
trumental en tanto expansión/incorporación de la lógica de la ciencia moderna como estructura de las prácticas sociales en los albores del Siglo XX. La aceptación “del desechar” como "patrón” de relación social ocupa, hoy, el lugar de la racionalidad formal y se ha extendido como arquitectura de toda interacción. Consumir es aprender a desechar y hoy esa es la práctica masiva en nuestras sociedades.

Como parte de la normalización de la sociedad y en su rol de gestora de emociones y constructora de sensibilidades, la política ha enfatizado en los primeros años de este siglosu rasgo de invertir a sabiendas el orden de las realidades posibles, constituyendo un doble registro/estándar en y sobre la acción. No es solamente que el político y en la política se miente, no se trata solamente de que se elaboren superficies de inscripción para valorar verdades ajustadas a intereses, o que solamente sea posible no cumplir/ acertar/realizar promesas. Lo que sucede es que se hace de todo esto un "estado de cosas" deseable. Son acciones cuyo objeto/efecto consiste en camuflar, en hacer pasar "una-cosa-por-otra", en negar lo que hay y en renegar de lo existente por exhibición, por demostración, por exuberancia. Son prácticas per-versas, prácticas del invertir por completo, enfatizar el revés. Estas son prácticas estatales, gestiones gubernamentales, consecuencias no intencionadas de la acción estatal. La política de la perversión consiste en el hecho de que el vínculo paradojal es establecido como eje de una estrategia de gestión de sensibilidades. Es la hiperbolización épica de la aceptación de que "nunca habrá nunca más".

En estos contextos se hilvanan las diversas formas de banalización del bien que implican la maximización del "cinismo" como estructura de la cotidiana aceptación de la imposibilidad. "Está bien”, “es bueno”, "hago bien" cuando acepto que lo posible es lo que debo hacer: el realismo político es llevado a su máxima expresión por medio de la sacralización de la noposibilidad. La banalización del bien es instaurar lo políticamente incorrecto como corrección política sabiendo que en ello se pierde el contenido y la forma de la incorrección, motivo por lo cual la actual forma de cinismo es una radical negación a lo que en él hay de crítica social. No estar "atrapado por las correcciones políticas” son las correcciones políticas en vigencia.

El bien como meta, como estado y como parámetro se desfonda, se des-realiza y disuelve no ya como única referencia colectiva sino y radicalmente como marca para la acción individual. La banalización del bien es el anverso solidario de la banalización del mal, construyendo un mundo donde lo único que vale es aquello que se establece vía mercantilización de las sensibilidades. Es la politización de la resignación cínica donde ya nada será "alcanzado" sin la negociación de su falla

El juego revolución/transformación/cambio es un claro ejemplo: lo que comenzó como la venta de las remeras del Che Guevara término en la revolución co-creada del cuidado del pelo femenino. No es solamente la negación de la realización totalizante de una acción,sino que se trata de la imposición substancializante de su radical imposibilidad a través de su 
masificación/vulgarización y la mega-reproducción de la pérdida de toda aura posible.

Justo en el "entre” que separa/une desecho/cinismo/perversión se ubican el conjunto de prácticas cuyas consecuencias "re-arman” una economía política de la moral, y a través de las cuales se gestionan las sensibilidades de la reproducción de lo dado.

Estas piezas nos permiten comprender parte de lo dibujado como escenarios y percibir, a su vez, la influencia de aquellos en las formas/ contenidos de las piezas mismas del puzzle.

\section{De prácticas y sujetos: “Saber tocar” y el Subsiadiano}

En tensión con los paisajes que componen los espacios delineados y la estructura de las sensibilidades esquematizada aparecen dos modificaciones del mundo social que se erigen como piezas fundantes del rompecabezas que estamos armando.

Dos de las transformaciones del siglo XX que seguramente cambiaran el siglo que comenzamos son: la relación con las máquinas y las modalidades de gestionar la coordinación de la acción de los sujetos en el campo de lo público/político.

\section{Saber tocar y las políticas de los sentidos}

Como ya hemos adelantado, una parte muy importante del rompecabezas del siglo XXI se recorta en torno a las sensibilidades:

1) Cerebro, nutrientes, disruptores endocrinos, nanogestión y manejo genómico de la vida son las aristas centrales de las condiciones materiales de vida del siglo XXI, los modos sociales para producir, concentrar y reproducir el poder sobre y desde estas aristas serán los objetos que demandarán indagaciones críticas sistemáticas.

2) Las formas sociales de la inmediatez conllevan superficies específicas donde se dan por sentadas condiciones de vivencialidades particulares y se suponen sociabilidades. Lo inmediato es un especial "aquí-ahora” que redefine el presente.

3) Las condiciones de productividad y la mercantilización de las sensaciones se unen en un "pre-origen" común que se elabora en "usar-elcuerpo" para relacionarse con las instrumentos/máquinas/aparatos.

Las prácticas sociales adquieren la textura de la materialidad del cuerpo/emoción, la densidad de la sensación y la procesualidad de los sentidos. 
Las formas sociales de conectarse con el mundo se han trasladado a las manos, a los dedos, a las yemas de los dedos en primer lugar con los instrumentos de comunicación, pero también con los medios de pago, los centros de entretenimiento y los aparatos para cocinar y limpiar. Literalmente vivimos presionando teclas, deslizando, tocando, “cliqueando"; así nuestro día-a-día está poblado de celulares, tarjetas de crédito, tarjetas de pago de transportes, cocinas, microondas, etc. que se han entrelazado entre las clases sociales, géneros, etnias y edades.

Unas sociedades que paradojalmente se espectaculariza y a la vez se reconcentra en lo individual, que se emociona "por todo" pero que se limita a los máspróximos, son sociedades que redefinen la política del tacto, las condiciones de las normas/reglas del tocar, tocarse y ser tocado.

Todas las políticas de los sentidos son actividades con la finalidad de resolver situaciones (sensu Thomas), de ser exitoso en la presentación social de la persona (sensu Goffman) y elaborar el conocimiento a la mano (sensu Schütz) que los sujetos usan en y desde el mundo de la vida. Es en el contexto de las citadas políticas que el tacto cobra relevancia.

Las relaciones sociales se han desplazado hacia una metáfora del tocar, del "touch", del "hacer clic", de interactuar con los instrumentos. Los sujetos se expresan desplazando, hundiendo partes sensibles de los aparatos y con esta acción más que ver o hacer hay que“saber tocar”. Esta es una aproximación a lo real que si bien no elimina el "saber cómo" y el "saber qué” (típicos de la disputa del siglo XX) redefine los accesos al mundo.

Una era post-cybor donde la línea entre superfluo, prótesis, extensión se diluye con la "amigabilidad" de las interfaces para comprar/disfrutar. El "saber tocar" más que una habilidad es una condición de posibilidad cognitiva/afectiva del estar en el mundo.

El siglo XXI será un siglo “del tocar” y las ciencias sociales tendrán la obligación de redefinir(se) en cuanto sus estrategias de indagación y discusiones ontológicas. En estos contextos, actor, agente, sujeto y autor se reconfigurarán, y consecuentemente se modificará también lo que hay en ellos de posicionalidad pública, dibujándose entonces otra pieza de nuestro puzzle.

\section{Subsidio más Ciudadanía: Subsiadano}

En la tensión entre ciudadano y consumidor va cobrando forma el subsiadano, una parte del rompecabezas recortada al talle de los desafíos para comprender "lo político" desde las ciencias sociales en el siglo XXI.

Para el año 2012 había en Latinoamerica 120.000.000 de personas que recibían una transferencia condicionada de ingresos y si se repara en las 
cifras de ciudadanos subsidiados en transportes y energía (solo para mencionar dos actividades) los millones no solo ascienden sino que devienen inexorablemente transclacistas. En la región, si tenemos en cuenta las actuales condiciones de asistencia estatal y estrategias de acción estatal, no sólo somos ciudadanos sino que somos subsidiados.

En ese contexto cobra relevancia la necesidad de reparar en las democracias constituidas en tornos a sujetos "compensados" (usando una analogía médica) y “contentos”, es decir tal como sugiere la etimología de la palabra, de individuos "contenidos". Se trata de prácticas estatales que establecen la resignación en tanto consecuencia de la lógica de la paciencia y la espera como "virtudes cívicas".

Las relaciones entre subsidio y ciudadanía se establecen a través de:

1. Un régimen consagración de derechos en tanto narraciones de desvinculación de/con lo real particular (sensu Marx)

2. Un régimen de articulación entre políticas sociales, políticas de las emociones e imágenes del mundo

3. La redefinición de las conexiones entre falta, consumo y sutura.

El subsiadiano vota como compra, compra como siente, siente como lo asisten. El Estado ya no es el único responsables de la políticas públicas, ahora es el mercado quien debe velar para que se reproduzcan los espacios subsidiados de la vida cotidiana en y a través de quienes producen lo que los subsidianos demandan.

La ampliación de las acciones estatales se efectivizan vía mercado: son los acuerdos con los capitales privados los que determinan las zonas subsidiadas en tanto centros neurálgicos de la reproducción del capital a largo plazo.

El estado "hace consumir" para que la empresa sea la responsable de la síntesis productor/consumidor naciendo así la condición de posibilidad de un subsiadiano racional: un "buscador de oportunidades" definido por su astucia para lograr consumir más a menor precio y mejorando el poder de compra de su ingreso.

El subsiadano es un componente fundamental de la financiarización de la vida cotidiana: todo en cuotas, todo en crédito. Es la masificación del hombre blanco clase media norteamericano que tiene su vida en cuotas y que "puede perderlo todo".

El capitalismo vuelve sobre sus pasos re-estructurando las relaciones ahorro/consumo/sacrificio/lujo/crédito. El siglo XXI es la tensión dialéctica entre dichas práctica a través de una economía política de la moral cuya columna vertebral son las sensibilidades. 
Cobrar, recibir y "usar" son las prácticas políticas del subsiadano: cobra por una práctica asociada a políticas públicas, recibe transferencias condicionadas de ingresos y utiliza los beneficios de los acuerdos Estado/ mercado. La participación en cooperativas, micro-emprendimientos, comedores, entre otras prácticas, hacen que los sujetos cobren una recompensa "a finde mes" (y con tarjeta bancaria) que los instala en una precariedad sistémica entre el empleo y trabajo. Los sujetos reciben montos actualizables de dinero por los cuales deben realizar acciones que garantizan la continuidad de la aludida recepción: llevar a los hijos a control médico, hacer que los mismos asistan a la escuela, etc. Los subsiadanos "disfrutan" de los subsidios dados a las empresas de gas, agua, energía, transporte público, etc. y que por su carácter "implícito" en las "tarifas" se viven como derechos cuando en realidad son oportunidades de negocio y aristas fundamentales de reproducción de la cadena consumo=subsidio=compensación= contención.

La dialéctica entre la pornografía del desecho, las políticas de la perversión, la banalización del bien a través del cinismo, el "saber tocar” y subsiadano nos desafían a pensar cómo indagaremos las pinturas del mundo que implican: emerge así otra pieza fundamental del rompecabezas.

\section{Metodología, Teoría y Epistemología}

El percibir teóricamente lo real, el fundar las proximidades/distancias entre mirar/ver/observar y las tareas necesarias para indagar lo social constituyen una pieza vital del puzzle que estamos bosquejando. Muchas son las aristas, las dimensiones y recursos que implican estas tareas del conocer.

Aquí vamos sólo ha mencionar tres transformaciones que apuntan a la re-articulación entre metodología, teoría y epistemología.

1. La modificación en el orden de lo metodológico: la palabra hablada es desplazada como medio privilegiado, casi único, para expresar el mundo, los otros y el yo.

2. La modificación en el orden de lo teórico: la necesidad de acercarse a una noción de autor que supere la de actor.

3. La modificación en el orden de lo epistémico: es la redefinición de la noción de verdad.

Estas modificaciones impactan en el contenido ético de la práctica sociológica y produce un abanico de redefiniciones en torno a los dualismos del siglo XX: revolución/contrarrevolución, producción/reproducción y/o transformación/conservación.El hacer de la sociología se modificará en torno a las consecuencias de las acciones sociológicas que intervienen en el mundo. Para unas ciencias sociales que recuperen su dictum de incomodi- 
dad y hacedor es necesario buscar unas imágenes de sujetos que se aproximen a las transformaciones "de la persona social" en la actualidad. Las ciencias sociales del siglo XXI son ciencias que se reconectan con su pasado como ingenierías sociales. Conocer/hacer es el eje de las ciencias más allá de la academia, donde se pierde por cinismo o por pragmatismo todo contenido utópico del conocer.

Es en este marco que, hace tiempo venimos bregando por la constitución de una estrategia de indagación social a la que hemos dado en llamar investigación basada en la creatividad/expresividad, pero también sabemos reconocer que las experiencias de expresividad no pueden ser reducidas a dicha estrategia. Lo que terminamos de presentar se inscribe en nuestra intensión de fundar, por distintas vía, unas estrategias de análisis de las sensibilidades que re-tomen las narraciones de los sujetos como material y eje del mismo. En el aludido escenario reflexivo es posible esbozar, al menos sintéticamente, algunas preguntas que sirvan de huellas para continuar profundizando la innovación en los procedimientos para captar sensaciones, emociones y sensibilidades:

a) Dado el marco del desarrollo masivo de las redes sociales y su uso para el marketing y el comercio electrónico ¿Cuáles serán los cruces futuros entre el análisis y construcción de preferencias y los estados de las sensibilidades en "las redes", en base a la creatividad/expresividad?

b) Si se parte de lo interrogado en a) la investigación social, su enseñanza/aprendizaje y las destrezas necesarias para indagar científicamente la sociedad desde la creatividad/expresividad ¿ Se modifican, se transforman?, y si la respuesta es sí ¿Qué deberíamos estudiar/aprehender?

c) En el contexto del manejo/gestión de las sensibilidades como práctica estructuradora que comparten tanto el Estado como el "mercado” ¿Cuáles serían las vías, procedimientos, técnicas más eficaces y eficientes para tomar las narraciones de los sujetos como punto de partida de las políticas gubernamentales/empresariales?

Estas tres preguntas pueden parecer insuficientes u obvias, pero lo que no se podrá negar es que tanto la metodología de la investigación como la teoría social y la epistemología, en los contextos aludidos, adquieren una relevancia social y política indiscutible.

Autor, expresión/creatividad y verdad serán los trazos centrales de una de las piezas claves de las modificaciones de las ciencias sociales a la luz de las alteraciones de un principio de siglo que busca su propio camino en la estructuración social.

\section{Sobre lo necesario: seguir rechazando}

En interacción con lo delineado y propuesto como puzzle de la co- 
nexiones/desconexiones entre estructuración social y ciencias sociales al comienzo del siglo XXI una pieza más aparece y re-toma valor: la crítica.

Un rompecabezas se define cuando el jugador puede ejercer su capacidad de intuir el "sentido" de totalidad que la pintura/paisaje implica pasando de los indicios particulares al contenido global, operando metonímicamente e imputando sentido a lo singular.

Las pinturas del mundo social que hemos podido esbozar, estas piezas (parciales y limitadas) de un puzzle sobre lo social nos demandan, siguiendo el dictum fundacional de las ciencias sociales, retomar una mirada crítica sobre lo construido.

Así aparecen las "topologías del rechazo" como un componente de radical importancia para un rompecabezas del conocer/hacer lo social.

Las topologías del rechazo son formas que componen unos campos de fuerzas contradictorios, unas morfologías de la negación y una cinta mobesiana de denegaciones. Decir que no, sostener la distancia, desmentir la resignación son prácticas que configuran la vida vivida en autonomía y tal vez la clave de las marchas futuras de lo colectivo.

Ni las prácticas intersticiales, ni las interdicciones colectivas, ni las experiencias de afirmación por si solas son suficientes para un acto inaugural de autonomía, tendremos que esforzar la sutileza de la observación para captar las nuevas situaciones donde se gesten topologías del rechazo a partir de la tensión mobesiana entre las tres.

Tal vez sean estas las mejores pistas para pensar el contenido de las acciones colectivas a principios del siglo XXI y con ellas las redefiniciones de unas ciencias sociales que deberán salir de las zonas de confort que elaboraron a lo largo del siglo XX. 
Polis, Revista Latinoamericana, Volumen 14, $N^{\circ} 41,2015$

\section{Notas}

1 Investigador Principal de CONICET. IIGG-UBA; Director del CIES (www.estudiosociologicos.org), Argentina.

${ }^{2}$ Como es de esperar, todas estas aristas del rompecabezas se comprenden mejor por el influjo del escenario argentino sobre quien escribe, lo cual sin duda hace que se relativice su posibilidad de generalización.

${ }^{3}$ Para disminuir al máximo las necesarias referencias bibliográficas y explicitar nuestro punto de partida lo elaborado por nosotros emerge del cruce entre realismo crítico dialectico (sensu Bhaskar) teoría crítica y hermenéutica crítica. A su vez las indagaciones empíricas que venimos realizando se han forjado en la articulación entre los estudios de acción colectiva, la crítica ideológica y una propuesta particular de una sociología de los cuerpos/emociones 


\section{Bibliografía}

Adorno, Th. y Horkheimer, M. (1998), Dialéctica de la Ilustración. Fragmentos filosóficos. Trotta, Madrid.

Bhaskar, R.A. (1993), Dialectic: The Pulse of Freedom, Verso, London.

Melucci, A. (1996), Challenging Codes: Collective Action in the Information Age, Cambridge University Press, Cambridge.

Thompson, Th. (1991), Critical Hermenutics, Cambridge University Press, Cambridge.

Scribano, A. (2013), Encuentros creativos expresivos:una metodología para estudiar sensibilidades. Estudios Sociológicos Editora, Buenos Aires.

Ídem (2013) (comp.), Teoría social, cuerpos y emociones. Estudios Sociológicos Editora, Buenos Aires

Ídem (2012), Teorías sociales del Sur: Una mirada post-independentista. Universitas - Editorial Científica Universitaria, Córdoba

Ídem (2009), Estudios sobre teoría social contemporánea. CICCUS, Buenos Aires

Ídem (1994), Teoría Social y Hermenéutica. CEAL, Buenos Aires

Scribano, A. y Lisdero, P. (2010), Sensibilidades en juego: miradas múltiples desde los estudios sociales de los cuerpos y las emociones. CEACONICET, Córdoba.

Scribano, A. y Figari, C. (2009), Cuerpo(s), Subjetividad(es) y Conflicto(s). Hacia una sociología de los cuerpos y las emociones desde Latinoamérica. CLACSO-CICCUS, Buenos Aires.

Zizek, S. (1989), The Sublime Object of Ideology. Verso, London.

Recibido: 10.08.2015

Aceptado: 25.08.2015 